\title{
Bio-Impedance Measurement Optimization for High-Resolution Carotid Pulse Sensing
}

\author{
Ting-Wei Wang ${ }^{1}{ }^{10}$, Hsiao-Wei Chu ${ }^{1}$, Lin Chou ${ }^{1}$, Yen-Ling Sung ${ }^{1}$, Yuan-Ta Shih ${ }^{2}$, Po-Chun Hsu ${ }^{2}$, \\ Hao-Min Cheng ${ }^{3,4,5}$ (D) and Shien-Fong Lin $1, * \mathbb{C}$
}

1 Institute of Biomedical Engineering, College of Electrical and Computer Engineering, National Chiao Tung University, Hsinchu 30010, Taiwan; w756704@gmail.com (T.-W.W.); eric31506@gmail.com (H.-W.C.); choulin.arete09@nctu.edu.tw (L.C.); debbysong20000@gmail.com (Y.-L.S.)

2 Research and Development Department VI, Smart Healthcare BU, Leadtek Research Inc.,

New Taipei 23511, Taiwan; yt_shih@leadtek.com.tw (Y.-T.S.); pochun_hsu@leadtek.com.tw (P.-C.H.)

3 Center for Evidence-Based Medicine, Department of Medical Education, Taipei Veterans General Hospital, Taipei 11217, Taiwan; hmcheng@vghtpe.gov.tw

4 Faculty of Medicine, National Yang-Ming University School of Medicine, Taipei 112304, Taiwan

5 Institute of Public Health and Community Medicine Research Center, National Yang-Ming University, Taipei 112304, Taiwan

* Correspondence: linsf5402@nctu.edu.tw

Citation: Wang, T.-W.; Chu, H.-W.; Chou, L.; Sung, Y.-L.; Shih, Y.-T.; Hsu, P.-C.; Cheng, H.-M.; Lin, S.-F. Bio-Impedance Measurement Optimization for High-Resolution Carotid Pulse Sensing. Sensors 2021, 21, 1600. https://doi.org/10.3390/ s21051600

Academic Editor: Juan Pablo Martínez

Received: 31 January 2021

Accepted: 19 February 2021

Published: 25 February 2021

Publisher's Note: MDPI stays neutral with regard to jurisdictional claims in published maps and institutional affiliations.

Copyright: (c) 2021 by the authors. Licensee MDPI, Basel, Switzerland. This article is an open access article distributed under the terms and conditions of the Creative Commons Attribution (CC BY) license (https:/ / creativecommons.org/licenses/by/ $4.0 /)$.

\begin{abstract}
Continuous hemodynamic monitoring is important for long-term cardiovascular healthcare, especially in hypertension. The impedance plethysmography (IPG) based carotid pulse sensing is a non-invasive diagnosis technique for measuring pulse signals and further evaluating the arterial conditions of the patient such as continuous blood pressure (BP) monitoring. To reach the high-resolution IPG-based carotid pulse detection for cardiovascular applications, this study provides an optimized measurement parameter in response to obvious pulsation from the carotid artery. The influence of the frequency of excitation current, electrode cross-sectional area, electrode arrangements, and physiological site of carotid arteries on IPG measurement resolution was thoroughly investigated for optimized parameters. In this study, the IPG system was implemented and installed on the subject's neck above the carotid artery to evaluate the measurement parameters. The measurement results within 6 subjects obtained the arterial impedance variation of $2137 \mathrm{~m} \Omega$ using the optimized measurement conditions, including excitation frequency of $50 \mathrm{kHz}$, a smaller area of $2 \mathrm{~cm}^{2}$, electrode spacing of $4 \mathrm{~cm}$ and $1.7 \mathrm{~cm}$ for excitation and sensing functions, and location on the left side of the neck. The significance of this study demonstrates an optimized measurement methodology of IPG-based carotid pulse sensing that greatly improves the measurement quality in cardiovascular monitoring.
\end{abstract}

Keywords: bio-impedance measurement; carotid pulse sensing; cardiovascular monitoring; continuous blood pressure; hemodynamics; impedance plethysmography (IPG)

\section{Introduction}

Cardiovascular diseases (CVDs) are one of the main causes of death, according to the World Health Organization (WHO) statistics [1]. Thus, continuous hemodynamic monitoring is important for long-term cardiovascular diagnoses such as hypertension, thus further providing the treatment methodology. In clinical application, the intra-arterial catheter is a common method to monitor hemodynamic parameters such as blood pressure (BP) and pulse rate. However, the intra-arterial catheter is an invasive method that could induce adverse complications for the patient [2,3]. Recently, wearable non-invasive biomedical sensors were proposed to address the adverse events of the arterial cannula and provide real-time hemodynamic parameters monitoring such as pressure pulse wave and continuous BP measurement [4-6], as shown in Table 1. 
Table 1. Comparison for different pulse measurement techniques.

\begin{tabular}{cccc}
\hline Technique & PPG & Pressure Sensor & IPG \\
\hline \multirow{2}{*}{ Mechanism } & light reflection or & mechanical to electrical & electrical impedance \\
transmission & conversion & measurement \\
Advantage & wearable application & ruggedness & deep region detection \\
Challenge & superficial artery & semi-occlusive & skin-electrode contact in \\
& & measurement & dry electrode \\
\hline
\end{tabular}

One of the proposed approaches relies on the photoplethysmography (PPG) method. The optical technique-based device is based on light reflection or transmission to detect volumetric changes in the blood. The PPG function was widely applied in wearable devices $[7,8]$ for heart rate [9] and BP [10] recording. However, the PPG approach could be applied only on the specific superficial artery such as the radial artery owing to the low penetration ability of light [11,12]. Other continuous hemodynamic monitoring techniques employ pressure sensors, including the capacitive pressure sensor and piezoelectric sensor. The capacitive pressure sensor measures arterial pulsation by detecting the distance change between two parallel plates and electrical capacitance $[13,14]$. The sandwich structure of the parallel plate capacitor has high stability, but the capacitive pressure sensors are typically characterized by low measurement sensitivities owing to the small variation of distance between the two electrodes [15]. For example, Kim et al. [16] presented a capacitive pressure sensor with the dielectric layer made of PDMS to enhance the measurement sensitivity of the sensor for BP monitoring. The piezoelectric sensor is based on the mechanicalelectrical conversion by piezoelectric-sensitive material of polyvinylidene fluoride (PVDF) film, thus arterial pressure signals can be depicted by electrical signals recording $[17,18]$. Wang et al. [19] provided a piezoelectric-based system to extract pressure pulse waves from the radial artery and further calculate the beat-to-beat BP measurement. However, the pressure sensor required sufficient external pressure between skin and sensor to ensure the coupling condition would not change during the measurement. The main limitation of the pressure sensor is caused by discomfort from semi-occlusive measurement that could not be suitable for long-term monitoring.

The impedance plethysmography (IPG) technique utilized the principle of electrical impedance to depict the continuous bio-impedance waveform under small alternating current excitation $[20,21]$. Compared to PPG and pressure sensors, the IPG technique could address the light penetration issue of the PPG sensor and semi-occlusive measurement of the pressure sensor owing to the mechanism of the electrical impedance measurement [22]. Some studies utilized the IPG-based technique to apply in continuous BP measurement [22,23] and deep veins of the leg monitoring [24]. In our previous study [25], a single-channel IPG neck patch device was developed and installed on the subject's neck above the carotid artery to perform cardiovascular monitoring, including the continuous $\mathrm{BP}$ and pulse rate.

This study mainly focused on investigating the influence of different measurement parameters on the measurement resolution of IPG-based carotid pulse sensing. The objective of this work is to determine the optimized condition that provides obvious physiological signals in response to arterial pulsation for improving the measurement quality in IPG-based cardiovascular applications. In this study, the different excitation frequencies, electrode area, electrode spacing, and physiological location were investigated to evaluate IPG measurement resolution.

The rest of this paper is organized as follows. Section 2 introduces the theoretical model of IPG-based carotid pulse sensing, IPG system design, bio-impedance calculation method for a carotid pulse, and experimental protocols. In Section 3, the results of different measurement parameters on IPG measurement resolution. In Sections 4 and 5, the discussions and conclusions were drawn. 


\section{Methods}

The flow chart of the methodology of our study was presented in Figure 1. First, the theoretical model of IPG-based carotid pulse measurement was established. Second, the IPG device was designed for testing the concept. Third, the calculation method for impedance change induced by carotid artery pulsation was provided. Forth, the influence of different measurement parameters on IPG-based arterial pulsation was evaluated to determine the optimized measurement solution for carotid pulse sensing.

Theoretical model of carotid artery pulsation sensing using IPG technique

IPG-based system design for carotid artery pulsation measurement

Calculation for impedance change induced by carotid artery pulsation

Figure 1. Flow chart of the IPG methodology for carotid pulse sensing.

\subsection{Theoretical Model of IPG-Based Carotid Artery Pulse Sensing}

The IPG measurement is based on the principle of electrical impedance that uses two pair electrodes placed on the selected body segments. The excitation electrodes employ a small alternating current that drives into the human body. The sensing electrodes are performed to extract the change in arterial impedance under continuous alternating current excitation. In arterial pulsation sensing, the IPG technique can extract real-time arterial impedance induced by blood volume changes in the artery during the diastole and systole phases, as shown in Figure 2. The arterial impedance can be categorized into basel impedance $\left(Z_{\text {basal }}\right)$ and shunting impedance induced by pulsation $\left(Z_{\text {pulsation }}\right)$. Based on Ohm's raw, $Z_{\text {basal }}$ and $Z_{\text {pulsation }}$ can be defined as Equations (1) and (2) by assuming that blood resistivity is consistent, arterial pulsation induced by blood volume change is uniform, and the driving currents are parallel with the carotid artery. In Equations (1) and (2), $\rho, \mathrm{L}, \mathrm{A}_{\text {basal }}, \Delta \mathrm{A}$ represent the blood resistivity, the measured length of the arterial segment, invariable basal cross-sectional area, and arterial cross-sectional area change of the artery:

$$
\begin{aligned}
& Z_{\text {basal }}=\rho \frac{L}{A_{\text {basal }}} \\
& Z_{\text {pulsation }}=\rho \frac{L}{\Delta A}
\end{aligned}
$$

The equivalent electrical model can regard as the $Z_{\text {basal }}$ and $Z_{\text {pulsation }}$ in parallel, according to Equation (3):

$$
\mathrm{Z}(\mathrm{t})=\left(\frac{1}{\mathrm{Z}_{\text {basal }}}+\frac{1}{\mathrm{Z}_{\text {pulsation }}}\right)^{-1}
$$

The change in arterial impedance of carotid artery induced by volume change can be acquired as Equation (4).

$$
\Delta Z=\left(Z_{\text {basal }}|| Z_{\text {pulsation }}\right)-Z_{\text {basal }}=-\frac{Z_{\text {basal }}^{2}}{Z_{\text {basal }}+Z_{\text {pulsation }}}
$$


Equation (5) can be simplified from Equation (4) by assuming that $Z_{\text {basal }}$ is much smaller than $Z_{\text {pulsation }}$ due to the larger cross-sectional area of $A_{\text {basal }}$ than $\Delta A$ [26] under the consistent blood resistivity and measured length of the arterial segment:

$$
\mathrm{Z}_{\text {pulsation }}=-\frac{\mathrm{Z}_{\text {basal }}^{2}}{\Delta \mathrm{Z}}
$$

Thus, the arterial impedance change induced by blood volume change can be derived as Equation (6), according to Equations (2) and (5):

$$
\Delta \mathrm{Z}=-\frac{\mathrm{Z}_{\text {basal }}^{2}}{\rho \mathrm{L}} \Delta \mathrm{A}
$$

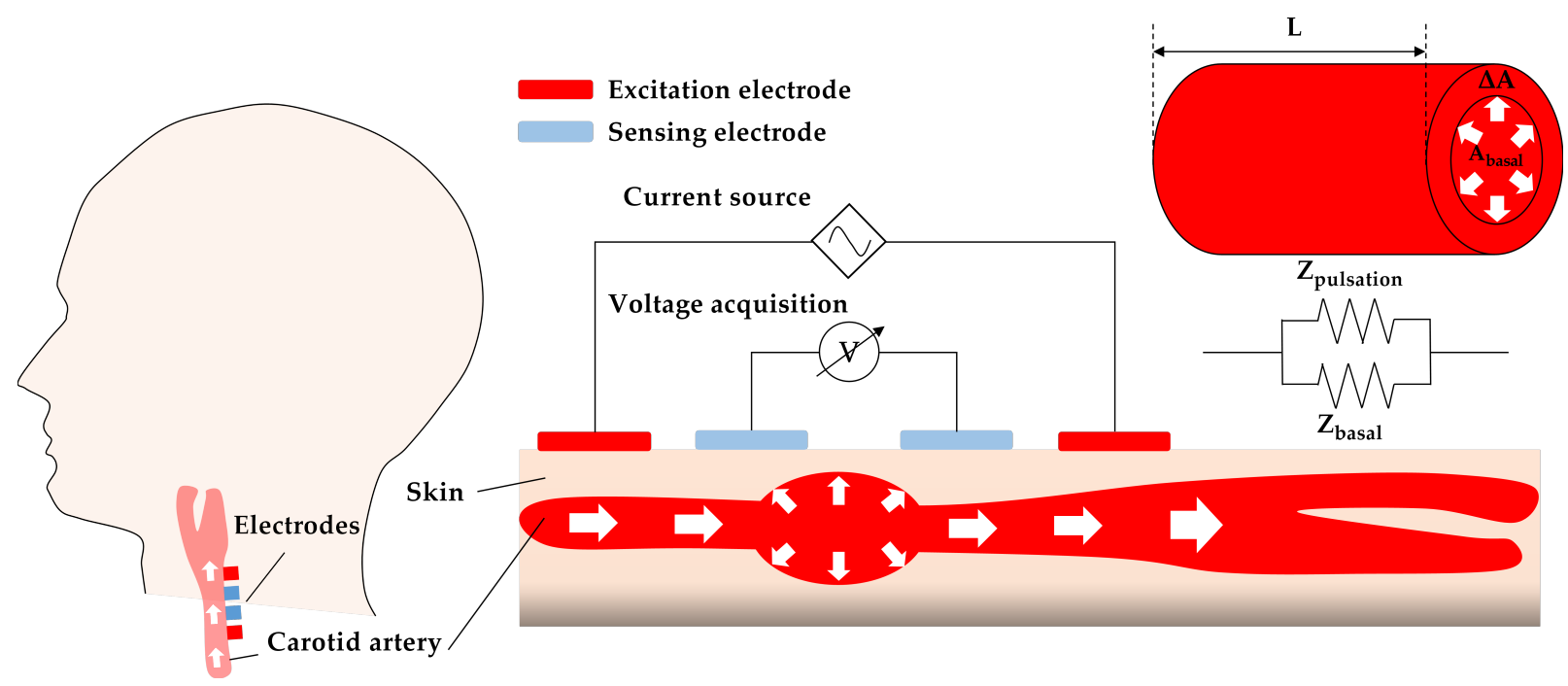

Figure 2. Schematic of IPG-based carotid pulse sensing and equivalent electrical model.

\subsection{IPG-Based System Design for Carotid Pulse Measurement}

Overall IPG system can be divided into three main parts, including electrodes, current source, and analog front-end (AFE), as shown in Figure 3. The wet-contact silver/silver chloride $(\mathrm{Ag} / \mathrm{AgCl})$ electrodes were utilized due to electrolytic gel with an excellent electrochemical characteristic $[27,28]$. The current source was implemented by a Wien-Bridge oscillator and an improved Howland current pump to produce an alternating current with an amplitude of $100 \mu \mathrm{A}$ and frequency of $50 \mathrm{kHz}$, which allows the safety guideline in the human body [29-31]. To measure arterial impedance change induced by small arterial pulsation, the AFE was implemented for enlarging the IPG signals. The pre-amplifiers with ultra-high impedance $10^{13} \Omega|| 1 \mathrm{pF}$ (OPA124, Texas Instruments, Dallas, TX, USA) are connected to sensing electrodes for avoiding voltage drop. An instrumentation amplifier (IA) (AD8421, Analog Devices Inc., Norwood, MA, USA) was used to detect the difference in input voltage between $\mathrm{V}_{+}$and $\mathrm{V}_{-}$. AD8421 provided a low input voltage noise of $3 \mathrm{nV} / \sqrt{ } \mathrm{Hz}$ and high common-mode rejection ratio (CMRR) of $110 \mathrm{~dB}$ and a gain of 989 at $50 \mathrm{kHz}$ to amplify IPG signals from the small arterial impedance change. To remove the $50 \mathrm{~Hz}$ carrier signals from alternating driving current, a demodulator IC (AD8310, Analog Devices Inc., Norwood, MA, USA) was utilized to extract the envelope signals induced by arterial pulsation. A four-order Butterworth bandpass filter was designed with a bandwidth from $0.3 \mathrm{~Hz}$ to $5 \mathrm{~Hz}$ to cover the range of pulse rate [32]. The analog IPG signals were transmitted into an analog-to-digital converter (ADC) for signal recording. The data acquisition module (myDAQ, National Instruments, Austin, TX, USA) provides a sampling rate of $500 \mathrm{~S} / \mathrm{s}$ and 16-bit resolution per channel. 


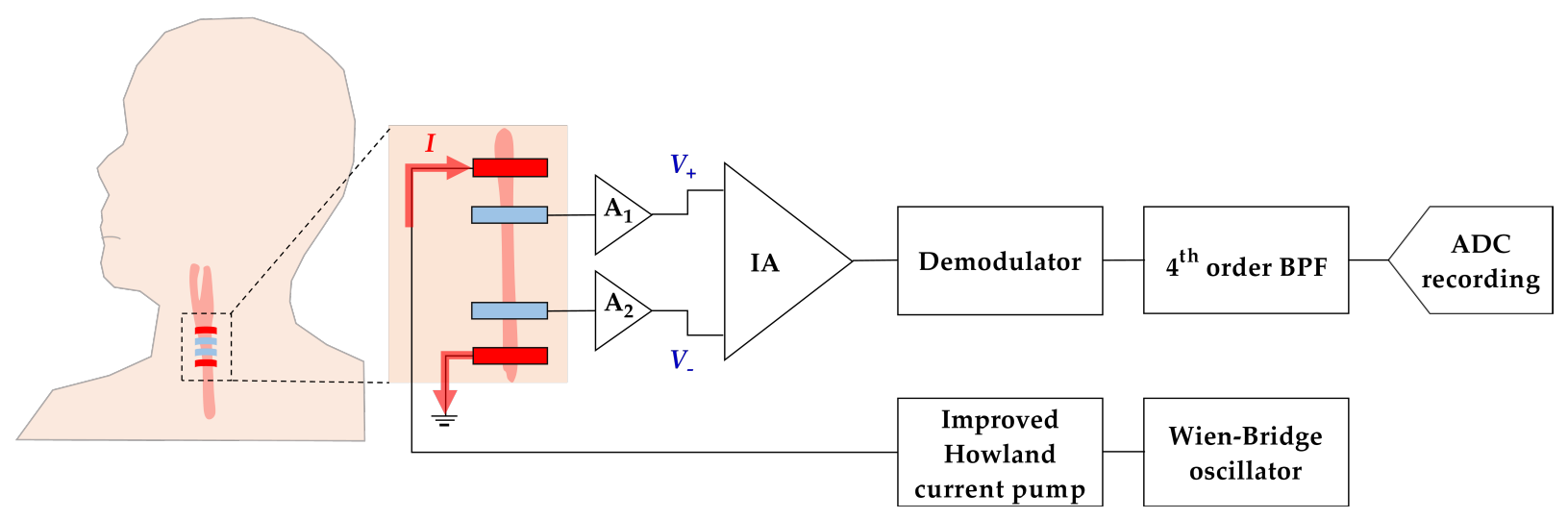

Figure 3. IPG system consists of two pairs of electrodes, two pre-amplifiers, instrumentation amplifier, demodulator, 4th order bandpass filter, Wien-Bridge oscillator, and improved Howland current pump.

\subsection{Calculation for Arterial Impedance Change}

To measure the arterial impedance change during the systolic phase (SP) and diastolic phase (DP), the proportional method was utilized for the impedance measurement, as shown in Figure 4 . The reference resistor of $R_{\text {ref }}$ was connected to the IPG electrodes and current source in series. Two instrumentation amplifiers $\left(\mathrm{IA}_{1}\right.$ and $\left.\mathrm{IA}_{2}\right)$ were used with the same components of OPA124. By assuming that the non-inverting and inverting terminals of IA can be neglected owing to ultra-high input impedance, thus ensuring the consistent current pass through the human body and reference resistor. Based on the Ohm's raw, the voltage difference $\left(\Delta V_{\text {ref }}\right)$ over the known resistor $R_{\text {ref }}$ was used to calculate the impedance change in the artery between systolic and diastolic phases $\left(\Delta Z_{\text {SP-DP }}\right)$ [21] through the measured voltage change in the artery $\left(\Delta \mathrm{V}_{\mathrm{SP}-\mathrm{DP}}\right)$, according to Equation (7):

$$
\Delta \mathrm{Z}_{\mathrm{SP}-\mathrm{DP}}=\mathrm{R}_{\mathrm{ref}} \frac{\Delta \mathrm{V}_{\mathrm{SP}-\mathrm{DP}}}{\Delta \mathrm{V}_{\text {ref }}}
$$

\section{Human body}

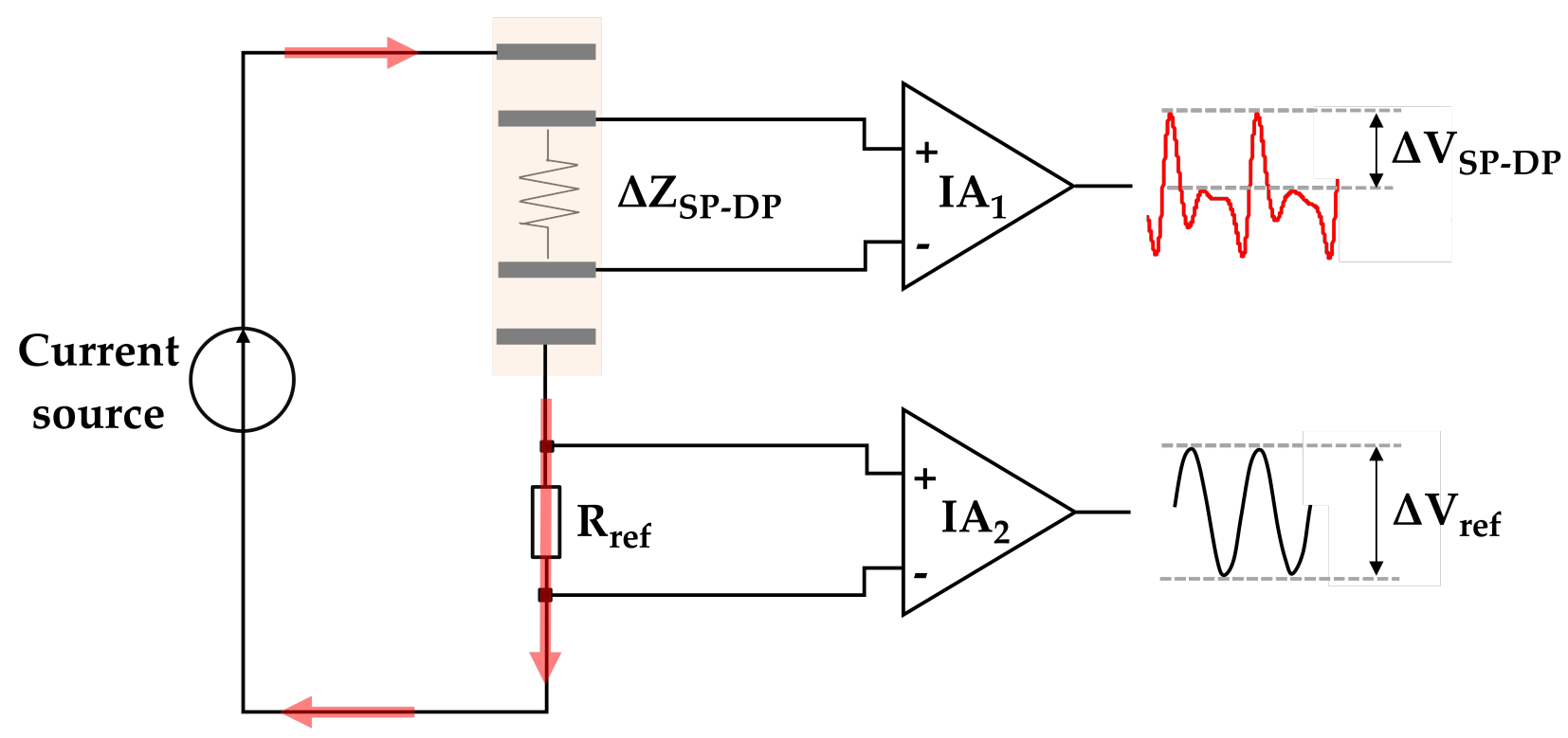

Figure 4. Schematic of the bio-impedance calculation method for the carotid pulse. 


\subsection{Ethics Statement and Experimental Design}

The experiment was permitted by the Institutional Review Board of National Chiao Tung University (NCTU-REC-109-012E). A total of six healthy subjects (three males and three females) participated in the experiment, with the age of $21 \pm 2$ years, the height of $168 \pm 9 \mathrm{~cm}$, the weight of $70 \pm 18 \mathrm{~kg}$. The measurement experiments were performed on the neck of the participants by medical tape (Nexcare ${ }^{\mathrm{TM}}$ Micropore $17003,3 \mathrm{M}^{\mathrm{TM}}$, St. Paul, MN, USA). In the installation of bio-impedance electrodes, two pieces of tape with the same length of $8 \mathrm{~cm}$ were used to attach the end of the electrodes to provide a consistent pressure during the bio-impedance measurement. All subjects agreed with the research ethics and were instructed to remain in a sitting position. The experimental flow chart was demonstrated to investigate the influence of measurement parameters (excitation frequency, electrode area, electrode spacing, and physiological location) on IPG resolution, as shown in Figure 5.

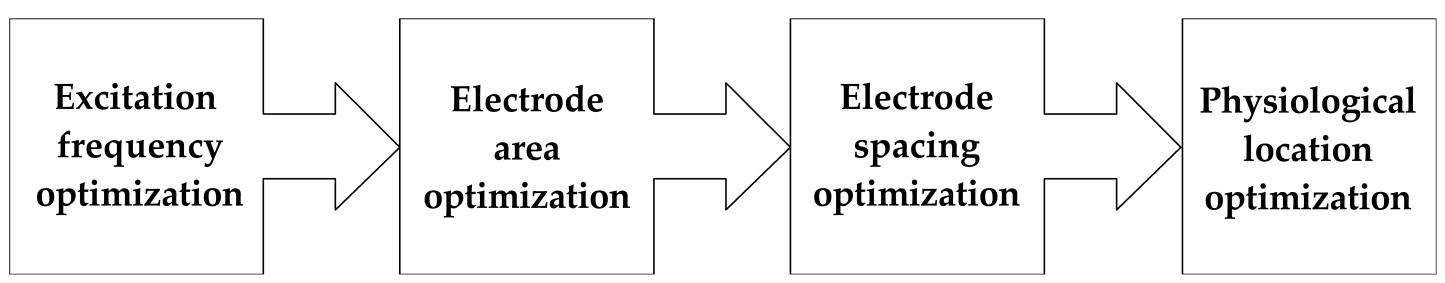

Figure 5. Flow chart of the step-by-step optimized procedure for measurement parameter.

\section{Experimental Results}

\subsection{Influence of Excitation Frequency on IPG Measurement Resolution}

The different frequencies of the driving current were performed $(10 \mathrm{kHz}-100 \mathrm{kHz})$ to evaluate the influence of excitation frequency on IPG measurement. In this assessment, the spacing of electrodes was an isometric arrangement with a spacing of $0.5 \mathrm{~cm}$ and the electrode area was $2 \mathrm{~cm}^{2}$. The electrode was placed above the right neck above the carotid artery of the subjects. Figure 6a demonstrates IPG morphology in different frequencies from $10 \mathrm{kHz}$ to $100 \mathrm{kHz}$ for subject 1 . Figure $6 \mathrm{~b}$ shows that a frequency of $50 \mathrm{kHz}$ obtained a larger impedance difference $\left(\Delta \mathrm{Z}_{\mathrm{SP}-\mathrm{DP}}\right)$ of $895 \mathrm{~m} \Omega$ than others.

\subsection{Influence of Electrode Area on IPG Measurement Resolution}

To investigate the IPG measurement resolution from arterial pulsation, the different electrode area from $2 \mathrm{~cm}^{2}$ to $4 \mathrm{~cm}^{2}$ was provided. In the measurement experiment, the electrode spacing and current excitation frequency were $0.5 \mathrm{~cm}$ and $50 \mathrm{kHz}$. The experimental results demonstrate that the smaller electrode cross-sectional area of $2 \mathrm{~cm}^{2}$ provided higher resolution $\left(\Delta Z_{\text {SP-DP }}=956 \mathrm{~m} \Omega\right)$, as shown in Figure 7 .

\subsection{Influence of Electrode Spacing on IPG Measurement Resolution}

The electrode placement also affects IPG measurement resolution [11,21]. To explore the influence of IPG electrode placement on the carotid artery, the spacing of excitation and sensing electrodes were evaluated for high-resolution IPG measurement. The excitation electrodes employ for conducting the driving current to pass through the artery regions. The spacing of the excitation electrode could affect the penetration depth of the current below the skin. To obtain the obvious impedance change in response to the arterial pulsation, the different spacing of excitation electrodes from $3 \mathrm{~cm}$ to $5 \mathrm{~cm}$ were evaluated. In this experiment, the spacing of the sensing electrode was determined by $0.5 \mathrm{~cm}$. Figure 8a shows that a spacing of $4 \mathrm{~cm}$ obtained a higher IPG measurement resolution $\left(\Delta \mathrm{Z}_{\mathrm{SP}-\mathrm{DP}}=1206 \mathrm{~m} \Omega\right)$. The sensing electrodes were utilized to detect the real-time arterial impedance under continuous and consistent current excitation. The variable spacing of sensing electrodes from $0.2 \mathrm{~cm}$ to $1.7 \mathrm{~cm}$ was provided to investigate the influence of sensing spacing on IPG measurement resolution. Figure $8 \mathrm{~b}$ shows that the impedance 
difference enlarged as increasing the distance of sensing electrodes. A spacing of $1.7 \mathrm{~cm}$ reached the better IPG measurement resolution of $\Delta Z_{\text {SP-DP }}=2015 \mathrm{~m} \Omega$.

\subsection{Influence of Left and Right Side Carotid Artery on IPG Measurement Resolution}

To investigate the influence of the carotid arteries in the left and right sides of the neck on IPG measurement, simultaneous IPG recording was performed in this study. Two same IPG systems were installed above the carotid arteries in right and left neck with consistent excitation frequency, electrode area, and electrode spacing. The comparison results show that the arterial impedance changes on the left side of the neck obtained a higher impedance difference of $2137 \mathrm{~m} \Omega$ than the right side of $1949 \mathrm{~m} \Omega$, as shown in Figure 9 .

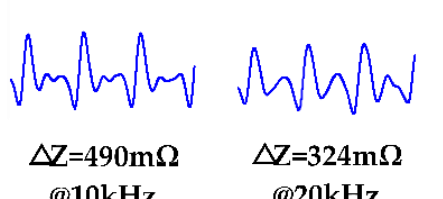
$@ 10 \mathrm{kHz}$

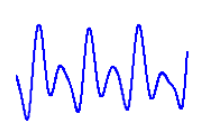

$\triangle \mathrm{Z}=500 \mathrm{~m} \Omega$ $@ 30 \mathrm{kHz}$
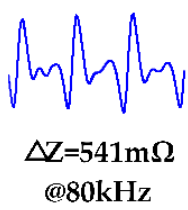

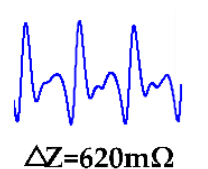

$@ 40 \mathrm{kHz}$
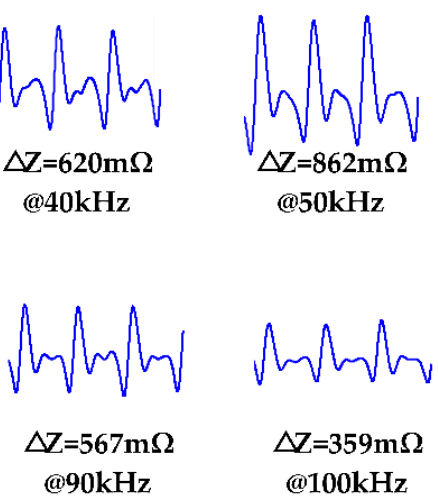

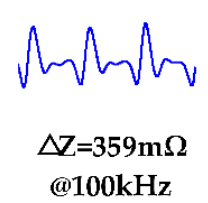

$320 \mathrm{~m} \Omega$

$40 \mathrm{~ms}$

(a)

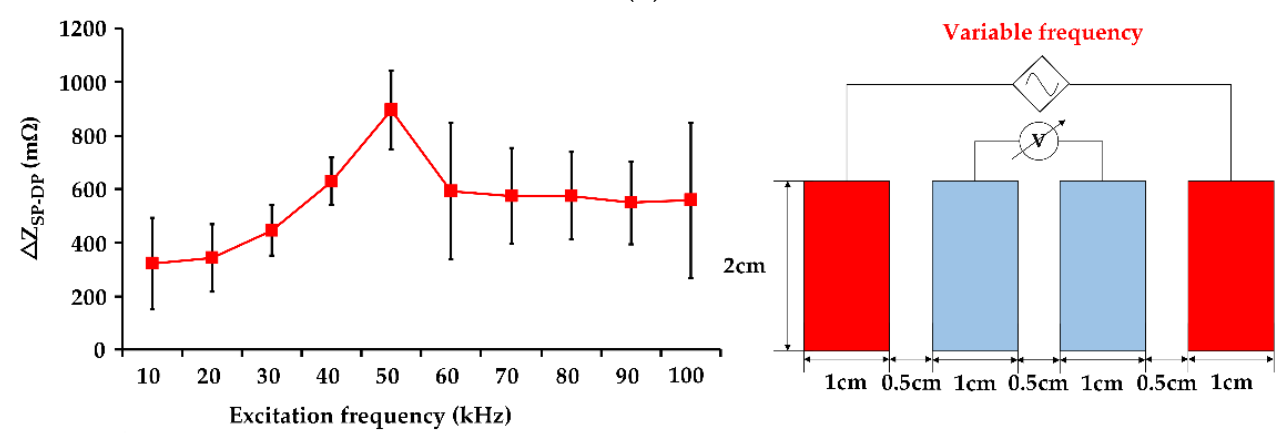

(b)

Figure 6. (a) IPG signals with excitation frequencies from $10 \mathrm{kHz}$ to $100 \mathrm{kHz}$ (Subject 1). (b) Statistical results for impedance variation in carotid pulse from $10 \mathrm{kHz}$ to $100 \mathrm{kHz}(\mathrm{n}=6)$.

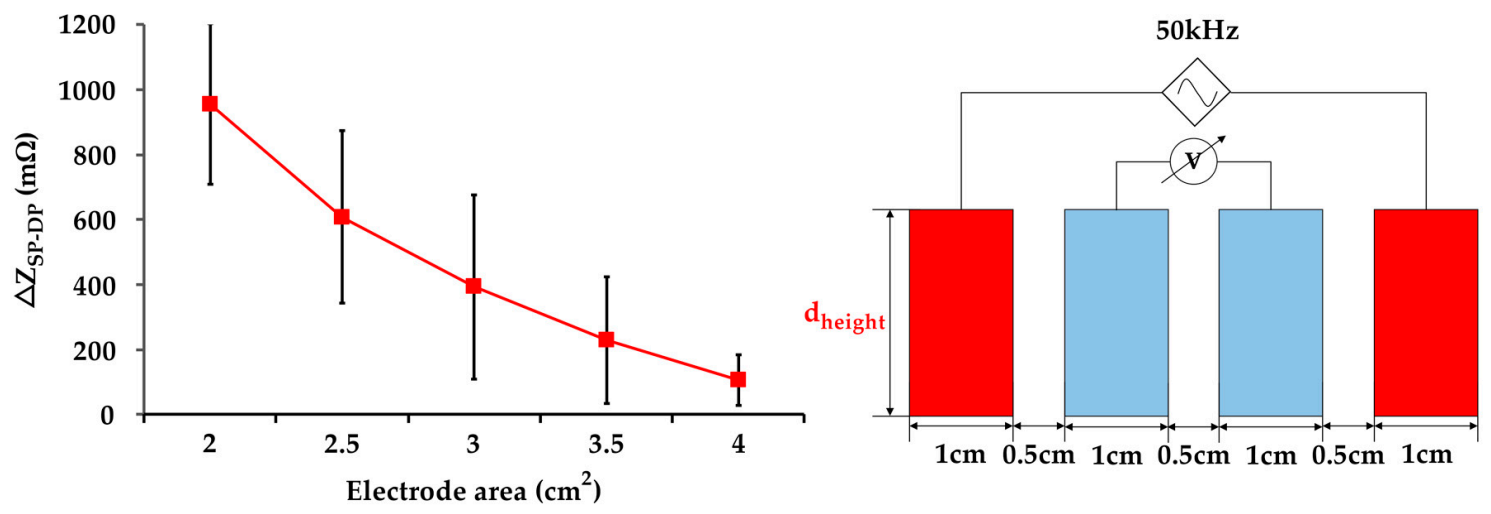

Figure 7. The influence of different electrode cross-sectional areas on IPG resolution measurement $(n=6)$. 

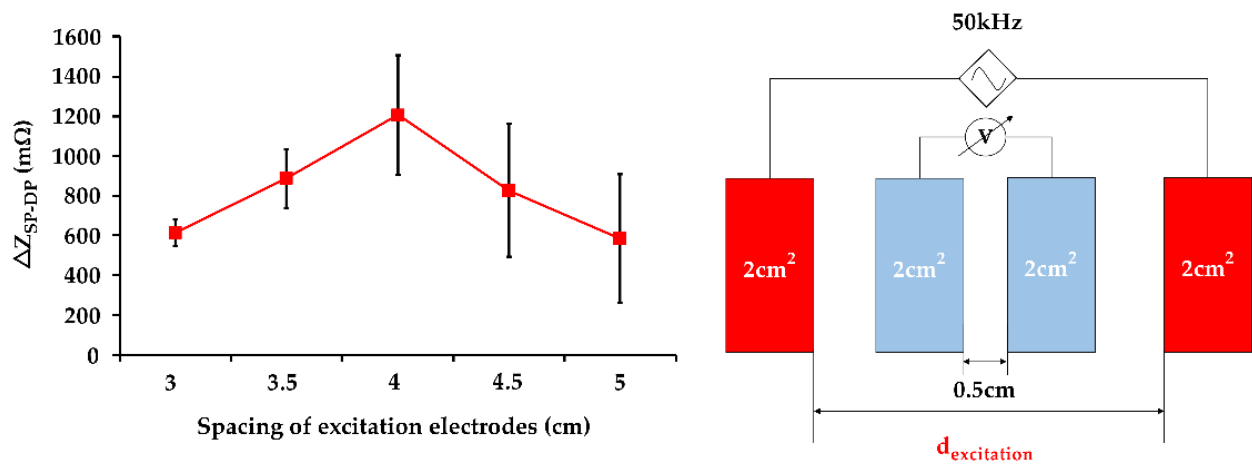

(a)
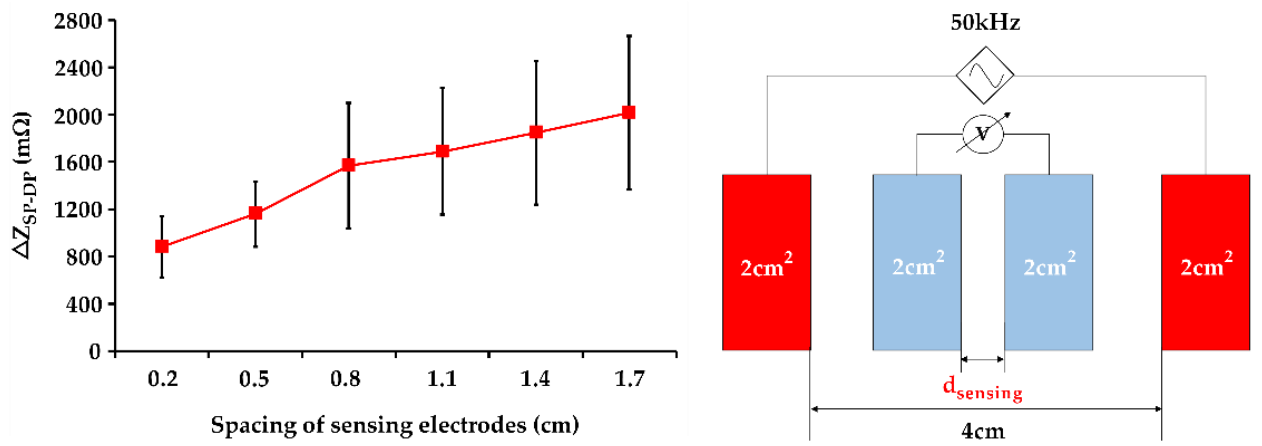

(b)

Figure 8. The influence of different (a) excitation spacing (from $3 \mathrm{~cm}$ to $5 \mathrm{~cm}$ ) and (b) sensing spacing (from $0.2 \mathrm{~cm}$ to $1.7 \mathrm{~cm}$ ) on IPG resolution measurement $(n=6)$.

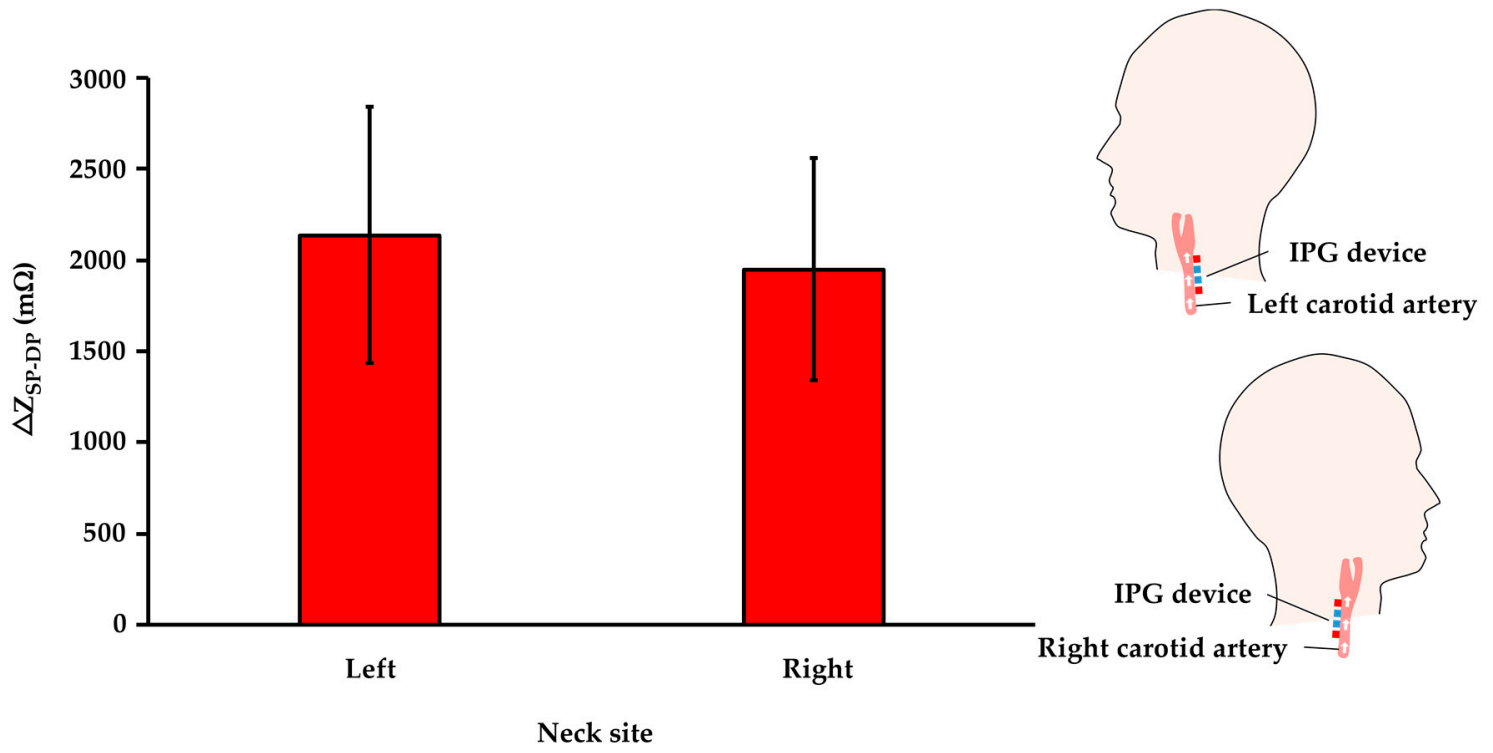

Figure 9. The comparison results of IPG measurement resolution between carotid arteries in the left and right sides $(\mathrm{n}=6)$. 


\section{Discussions}

\subsection{Significance in IPG-Base Carotid Pulse Sensing}

The IPG-based carotid pulse sensing is useful for diagnosing hemodynamic parameters such as continuous BP. The IPG-based signals from the carotid artery deliver the pulse signals with the variation in arterial pressure and blood volume per heartbeat. The surficial carotid artery was selected for IPG physiological measurement location owing to palpable pressure pulse and the measurement location near the central aorta. The strong arterial pulsation from the carotid artery represents the larger blood volume changes in response to obvious impedance change by IPG sensing, according to Equation (6). Also, the measurement location of the carotid artery is near the central aorta. The central aortic pressure (CAP) reflected the true load imposed on the heart and large arteries rather than peripheral arteries [33]. However, the pressure signals of the central arteries must be extracted from the further transformation of alternative waveforms for non-invasive measurement techniques [26]. Compared to branchial and radial arteries, the waveform morphology of the carotid artery was similar to the aorta owing to the site near the aortic artery with lower pressure distortion [34]. Based on the physiological aspect of noninvasive hemodynamic monitoring, the IPG-based carotid artery has a high potential for cardiovascular applications.

\subsection{Influence of Measurement Parameters on IPG Measurement Resolution}

To this end, this study mainly researched the influence of measurement parameters on IPG-based carotid pulse measurement. In this study, the four approaches were provided for high-resolution IPG measurement of six participants, including (1) excitation frequency of the current source, (2) electrode area, (3) arrangements for excitation and sensing electrodes, and (4) physiological location of the carotid arteries. The Fricke-Morse model indicates that the excitation frequency of the current source affects biological impedance measurement $[35,36]$. The test frequencies from $10 \mathrm{kHz}$ to $100 \mathrm{kHz}$ were performed to evaluate the excitation frequencies on IPG measurement. The frequency of $50 \mathrm{kHz}$ was the most effective excitation frequency in response to the obvious impedance change $\left(\Delta Z_{\text {SP-DP }}\right)$ of $895 \mathrm{~m} \Omega$, as shown in Figure 6. Some studies indicated the frequency of $50 \mathrm{kHz}$ was the most efficient excitation parameter for bio-impedance measurement, resulting in the high penetration depth through intracellular and extracellular fluids $[37,38]$. Besides, the electrode area was investigated for IPG-based carotid pulse sensing. The different electrode areas from $2 \mathrm{~cm}^{2}$ to $4 \mathrm{~cm}^{2}$ were tested to assess the IPG measurement resolution. Figure 7 shows that the IPG resolution was inversely correlated to the electrode area. The smaller electrode area of $2 \mathrm{~cm}^{2}$ obtained the higher $\Delta Z_{\text {SP-DP }}$ of $956 \mathrm{~m} \Omega$ owing to voltage sensing at a specified location [39]. In contrast, the large area obtained the lower impedance change from carotid artery pulsation, which was attributed to the lower spatial resolution from IPG measurement under the large active area of electrodes. The electrode placing arrangement was also important for IPG measurement. Some studies also investigated the optimized spacing of electrodes for IPG-based radial artery applications [22,40]. This study focused on the carotid artery to evaluate the influence of electrode arrangement (excitation and sensing electrode pairs) on IPG measurement resolution. The optimized excitation electrode placing can greatly confine the electrical current pass through the region of the carotid artery and then obtain the high-resolution IPG waveform. Figure 8a demonstrates that a spacing of $4 \mathrm{~cm}$ obtained an obvious impedance variation of $1206 \mathrm{~m} \Omega$ at testing excitation spacing from $3 \mathrm{~cm}$ to $5 \mathrm{~cm}$. The spacing between two excitation electrodes would influence the measuring depth [41]. The narrow spacing within two excitation electrodes could pass through the superficial surface rather than the arterial region. The longer spacing within the excitation electrodes could decrease the current uniformity in the arterial region. For the consideration of sensing electrode spacing, the IPG measurement resolution was improved by increasing the spacing of sensing electrodes due to larger voltage differences under the consistent current source [22]. As shown in Figure 8b, the IPG measurement resolution was positively correlated to the spacing of sensing electrodes and a spacing of $1.7 \mathrm{~cm}$ obtained 
the maximum impedance difference of $2015 \mathrm{~m} \Omega$ at testing sensing spacing from $0.2 \mathrm{~cm}$ to $1.7 \mathrm{~cm}$. Most of all, this study investigated the influence of different sides of carotid arteries on IPG measurement resolution, as shown in Figure 9. The comparison results demonstrate the carotid artery on the left side obtained a higher $\Delta \mathrm{Z}_{\mathrm{SP}-\mathrm{DP}}$ of $2137 \mathrm{~m} \Omega$ than the right side of $1949 \mathrm{~m} \Omega$. The larger arterial pulse from the left common carotid artery (CCA) was attributed to a direct branch from the arch of the aorta. Compare to the left CCA, the right CCA is a branch of the brachiocephalic trunk [42,43]. Thus, the physiological asymmetry in the left and right carotid could induce the difference in impedance variation during the bio-impedance measurement.

\subsection{Comparison with Related IPG Studies}

We compared the IPG-based impedance variation results between previous studies and our work, as shown in Table 2 . Based on Table 2, most studies $[21,40,44]$ utilized the IPG-based wrist method to measure the IPG signals from the radial artery and investigated the influence of various measurement locations on impedance variation under the consistent excitation frequency and electrode area. Wang et al. [22] evaluated the influence of electrode spacing and excitation frequency on impedance variation in the radial artery. However, the measurement optimization of IPG-based carotid artery sensing has not been extensively investigated. Compared to the previous works, this study comprehensively evaluated the influence of the measurement parameters on IPG measurement resolution for carotid pulse sensing, resulting in an optimized result of $2137 \mathrm{~m} \Omega$. The robust performance of impedance variation could be attributed to the strong pulsation of the carotid artery in the physiological aspect than radial artery (Section 4.1). Importantly, the major contribution of our work is to optimize the measurement conditions of the excitation frequency, electrode area, electrode spacing, and physiological location for high-resolution IPG carotid pulse measurement (Section 4.2).

Table 2. Performance comparison for IPG-based arterial pulse measurement.

\begin{tabular}{clcc}
\hline Author & Artery & Participants & $\Delta \mathbf{Z}_{\max }$ \\
\hline Cho et al. [44] & radial artery & 2 healthy subjects & $131.1 \mathrm{~m} \Omega$ \\
Huynh et al. [21] & radial artery & 15 healthy subjects & $325.8 \mathrm{~m} \Omega$ \\
Huynh et al. [40] & radial artery & 15 healthy subjects & $67.1 \mathrm{~m} \Omega$ \\
Wang et al. [22] & radial artery & 30 healthy subjects & $594 \mathrm{~m} \Omega$ \\
Our work & carotid artery & 6 healthy subjects & $2137 \mathrm{~m} \Omega$ \\
\hline
\end{tabular}

\subsection{Limitations}

Although this study demonstrates the influence of excitation frequency, electrode spacing, and physiological location on bio-impedance measurement, some limitations require further investigation in the future. First, the specific applied pressure on electrodes from medical tape needs to further evaluate for accurate bio-impedance measurement. Second, the mechanical stimulation of the carotid artery such as electrode installation could induce the carotid sinus reflexes, resulting in a small fall in heart rate and BP $[45,46]$. Third, recruit more subjects with hypertensive and hypotensive patients to further investigate the significant differences in $\Delta Z_{\text {SP-DP }}$ between different group conditions. Fourth, in Figure 7 , the influence of lower electrode area $\left(<2 \mathrm{~cm}^{2}\right)$ on IPG measurement resolution needs to further investigate whether the $\Delta \mathrm{Z}_{\mathrm{SP}-\mathrm{DP}}$ would become saturation until the $\mathrm{d}_{\text {height }}$ of testing electrodes approaches the width of the carotid artery.

\section{Conclusions}

This study investigated the influence of measurement parameters on IPG-based carotid pulse sensing. The excitation frequency, electrode cross-sectional area, electrode spacing, and physiological measurement site were evaluated for high-resolution IPG measurement in response to obvious carotid arterial pulsation. The measurement performance of six subjects obtained the obvious impedance variation of $2137 \mathrm{~m} \Omega$ by excitation frequency 
of $50 \mathrm{kHz}$, electrode area of $2 \mathrm{~cm}^{2}$, excitation and sensing electrode spacing of $4 \mathrm{~cm}$ and $1.7 \mathrm{~cm}$, and carotid artery on the left side. The main contribution of this study is to provide an optimized measurement condition of IPG-based carotid pulse sensing that improved the measurement quality in hemodynamic applications such as long-term BP monitoring.

Author Contributions: T.-W.W. conceived of the presented idea, supervised the experiment progress and wrote the manuscript. H.-W.C. and L.C. performed the experiment and validation. Y.-L.S. performed the data analysis and graphing. Y.-T.S., P.-C.H. and H.-M.C. provided the resources and funding. S.-F.L. supervised the project and reviewed the manuscript. All authors have read and agreed to the published version of the manuscript.

Funding: This work was supported by the University-Industry Collaboration (National Chiao Tung University and Leadtek Research Inc.) under Grant 109A159.

Institutional Review Board Statement: The study was conducted according to the guidelines of the Declaration of Helsinki, and approved by the Institutional Review Board of National Chiao Tung University (approval numbers: NCTU-REC-109-012E).

Informed Consent Statement: Informed consent was obtained from all subjects involved in the study.

Data Availability Statement: The data presented in this study are available on request from the corresponding author.

Conflicts of Interest: The authors declare no conflict of interest.

\section{References}

1. Maarman, G.J.; Chakafana, G.; Sliwa, K. World Heart Day: A World Heart Federation Communiqué on the Future of Basic Sciences and Translational Medicine in Global Cardiovascular Research; American Physiological Society: Bethesda, MD, USA, 2020.

2. Kitterman, J.A.; Phibbs, R.H.; Tooley, W.H. Catheterization of umbilical vessels in newborn infants. Pediatr. Clin. N. Am. 1970, 17, 895-912. [CrossRef]

3. McEniery, C.M.; Cockcroft, J.R.; Roman, M.J.; Franklin, S.S.; Wilkinson, I.B. Central blood pressure: Current evidence and clinical importance. Eur. Heart J. 2014, 35, 1719-1725. [CrossRef]

4. Dias, D.; Paulo Silva Cunha, J. Wearable Health Devices-Vital Sign Monitoring, Systems and Technologies. Sensors 2018, $18,2414$. [CrossRef]

5. Ding, X.R.; Zhao, N.; Yang, G.Z.; Pettigrew, R.I.; Lo, B.; Miao, F.; Li, Y.; Liu, J.; Zhang, Y.T. Continuous Blood Pressure Measurement From Invasive to Unobtrusive: Celebration of 200th Birth Anniversary of Carl Ludwig. IEEE J. Biomed. Health Inform. 2016, 20, 1455-1465. [CrossRef]

6. Zheng, Y.L.; Ding, X.R.; Poon, C.C.; Lo, B.P.; Zhang, H.; Zhou, X.L.; Yang, G.Z.; Zhao, N.; Zhang, Y.T. Unobtrusive sensing and wearable devices for health informatics. IEEE Trans. Bio-Med. Eng. 2014, 61, 1538-1554. [CrossRef] [PubMed]

7. Khan, Y.; Han, D.; Ting, J.; Ahmed, M.; Nagisetty, R.; Arias, A.C. Organic Multi-Channel Optoelectronic Sensors for Wearable Health Monitoring. IEEE Access 2019, 7, 128114-128124. [CrossRef]

8. Lochner, C.M.; Khan, Y.; Pierre, A.; Arias, A.C. All-organic optoelectronic sensor for pulse oximetry. Nat. Commun. 2014, 5, 5745. [CrossRef]

9. Poh, M.Z.; Poh, Y.C. Validation of a Standalone Smartphone Application for Measuring Heart Rate Using Imaging Photoplethysmography. Telemed. J. e-Health Off. J. Am. Telemed. Assoc. 2017, 23, 678-683. [CrossRef]

10. Tabei, F.; Gresham, J.M.; Askarian, B.; Jung, K.; Chong, J.W. Cuff-Less Blood Pressure Monitoring System Using Smartphones. IEEE Access 2020, 8, 11534-11545. [CrossRef]

11. Pesti, K.; Metshein, M.; Annus, P.; Kõiv, H.; Min, M. Electrode Placement Strategies for the Measurement of Radial Artery Bioimpedance: Simulations and Experiments. IEEE Trans. Instrum. Meas. 2020, 70, 1-10. [CrossRef]

12. Raghunath, M.; Kiran, V.; Aravapalli, S. Design of an Optical Blood Pressure Sensor for Noninvasive Monitoring of Blood Pressure. Int. J. Sci. Eng. Adv. Technol. 2015, 3, 1112-1117.

13. Yang, X.; Wang, Y.; Qing, X. A Flexible Capacitive Pressure Sensor Based on Ionic Liquid. Sensors 2018, 18, 2395. [CrossRef]

14. Rao, K.S.; Samyuktha, W.; Vardhan, D.V.; Naidu, B.G.; Kumar, P.A.; Sravani, K.G.; Guha, K. Design and sensitivity analysis of capacitive MEMS pressure sensor for blood pressure measurement. Microsyst. Technol. 2020, 26, 2371-2379. [CrossRef]

15. Ma, L.; Yu, X.; Yang, Y.; Hu, Y.; Zhang, X.; Li, H.; Ouyang, X.; Zhu, P.; Sun, R.; Wong, C.-P. Highly sensitive flexible capacitive pressure sensor with a broad linear response range and finite element analysis of micro-array electrode. J. Mater. 2020, 6, 321-329. [CrossRef]

16. Kim, J.; Chou, E.F.; Le, J.; Wong, S.; Chu, M.; Khine, M. Soft Wearable Pressure Sensors for Beat-to-Beat Blood Pressure Monitoring. Adv. Healthc. Mater. 2019, 8, e1900109. [CrossRef] 
17. Liu, Z.D.; Liu, J.K.; Wen, B.; He, Q.Y.; Li, Y.; Miao, F. Cuffless Blood Pressure Estimation Using Pressure Pulse Wave Signals. Sensors 2018, 18, 4227. [CrossRef] [PubMed]

18. McLaughlin, J.; McNeill, M.; Braun, B.; McCormack, P.D. Piezoelectric sensor determination of arterial pulse wave velocity. Physiol. Meas. 2003, 24, 693-702. [CrossRef]

19. Wang, T.W.; Lin, S.F. Wearable Piezoelectric-Based System for Continuous Beat-to-Beat Blood Pressure Measurement. Sensors 2020, 20, 851. [CrossRef] [PubMed]

20. Liu, S.H.; Cheng, D.C.; Su, C.H. A Cuffless Blood Pressure Measurement Based on the Impedance Plethysmography Technique. Sensors 2017, 17, 1176. [CrossRef]

21. Huynh, T.H.; Jafari, R.; Chung, W.-Y. An Accurate Bioimpedance Measurement System for Blood Pressure Monitoring. Sensors 2018, 18, 95. [CrossRef] [PubMed]

22. Wang, T.W.; Chen, W.X.; Chu, H.W.; Lin, S.F. Single-channel Bio-impedance Measurement for Wearable Continuous Blood Pressure Monitoring. IEEE Trans. Instrum. Meas. 2020, 1. [CrossRef]

23. Ibrahim, B.; Jafari, R. Cuffless Blood Pressure Monitoring from an Array of Wrist Bio-Impedance Sensors Using Subject-Specific Regression Models: Proof of Concept. IEEE Trans. Biomed. Circuits Syst. 2019, 13, 1723-1735. [CrossRef] [PubMed]

24. Weyer, S.; Weber, H.; Kleeberg, C.; Leonhardt, S.; Wartzek, T. Development of a real-time, semi-capacitive impedance phlebography device. J. Electr. Bioimpedance 2015, 6, 2-9. [CrossRef]

25. Wang, T.W.; Chu, H.W.; Chen, W.X.; Shih, Y.T.; Hsu, P.C.; Cheng, H.M.; Lin, S.F. Single-Channel Impedance Plethysmography Neck Patch Device for Unobtrusive Wearable Cardiovascular Monitoring. IEEE Access 2020, 8, 184909-184919. [CrossRef]

26. Soleimani, E.; Mokhtari-Dizaji, M.; Fatouraee, N.; Saberi, H. Assessing the blood pressure waveform of the carotid artery using an ultrasound image processing method. Ultrasonography 2017, 36, 144-152. [CrossRef] [PubMed]

27. Chi, Y.; Jung, T.-P.; Cauwenberghs, G. Dry-Contact and Noncontact Biopotential Electrodes: Methodological Review. Biomed. Eng. IEEE Rev. 2010, 3, 106-119. [CrossRef] [PubMed]

28. Fu, Y.; Zhao, J.; Dong, Y.; Wang, X. Dry Electrodes for Human Bioelectrical Signal Monitoring. Sensors 2020, 20, 3651. [CrossRef]

29. Anand, G.; Lowe, A.; Al-Jumaily, A. Simulation of impedance measurements at human forearm within $1 \mathrm{kHz}$ to $2 \mathrm{MHz}$. J. Electr. Bioimpedance 2016, 7, 20. [CrossRef]

30. Stahn, A.; Terblanche, E.; Gunga, H.-C. Use of Bioelectrical Impedance: General Principles and Overview. In Handbook of Anthropometry: Physical Measures of Human Form in Health and Disease; Preedy, V.R., Ed.; Springer: New York, NY, USA, 2012; pp. 49-90. [CrossRef]

31. Naranjo-Hernández, D.; Reina-Tosina, J.; Min, M. Fundamentals, Recent Advances, and Future Challenges in Bioimpedance Devices for Healthcare Applications. J. Sens. 2019, 2019, 9210258. [CrossRef]

32. Wang, J.-J.; Wei-Chih, H.; Kao, T.; Liu, C.-P.; Lin, S.-K. Development of forearm impedance plethysmography for the minimally invasive monitoring of cardiac pumping function. J. Biomed. Sci. Eng. 2011, 4, 122-129. [CrossRef]

33. Min, M.; Kõiv, H.; Priidel, E.; Pesti, K.; Annus, P. Noninvasive Acquisition of the Aortic Blood Pressure Waveform. In Wearable Devices-The Big Wave of Innovation; IntechOpen: London, UK, 2019.

34. Brandão, A.A.; Amodeo, C.; Alcântara, C.; Barbosa, E.; Nobre, F.; Pinto, F.; Vilela-Martin, J.F.; Bastos, J.M.; Yugar-Toledo, J.C.; Mota-Gomes, M.A.; et al. I Luso-Brazilian positioning on central arterial pressure. Arquivos brasileiros de cardiologia 2017, 108, 100-108. [CrossRef] [PubMed]

35. Sanchez, B.; Bandarenka, A.S.; Vandersteen, G.; Schoukens, J.; Bragos, R. Novel approach of processing electrical bioimpedance data using differential impedance analysis. Med. Eng. Phys. 2013, 35, 1349-1357. [CrossRef] [PubMed]

36. Zhang, F.; Sanchez, B.; Rutkove, S.B.; Yang, Y.; Zhong, H.; Li, J.; Teng, Z. Numerical estimation of Fricke-Morse impedance model parameters using single-frequency sinusoidal excitation. Physiol. Meas. 2019, 40, 09nt01. [CrossRef] [PubMed]

37. Bera, T.K. Bioelectrical Impedance Methods for Noninvasive Health Monitoring: A Review. J. Med. Eng. 2014, $2014,381251$. [CrossRef]

38. Hassan, Y.; Eldosoky, M.A.; El-Wakad, M.T.I. The effect of vascular diseases on bioimpedance measurements: Mathematical modeling. Biomed. Res. Ther. 2018, 5, 2414-2431.

39. Chitturi, V.; Farrukh, N. Spatial resolution in electrical impedance tomography: A topical review. J. Electr. Bioimpedance 2017, 8, 66-78. [CrossRef]

40. Huynh, T.H.; Jafari, R.; Chung, W.Y. Noninvasive Cuffless Blood Pressure Estimation Using Pulse Transit Time and Impedance Plethysmography. IEEE Trans. Bio-Med. Eng. 2019, 66, 967-976. [CrossRef] [PubMed]

41. Grimnes, S.; Martinsen, Ø.G. Chapter 6-Geometrical Analysis. In Bioimpedance and Bioelectricity Basics, 3rd ed.; Grimnes, S., Martinsen, Ø.G., Eds.; Academic Press: Oxford, UK, 2015; pp. 141-178. [CrossRef]

42. Jacob, S. Chapter 7-Head and neck. In Human Anatomy; Jacob, S., Ed.; Churchill Livingstone: London, UK, 2008; pp. 181-225. [CrossRef]

43. Tahmasebpour, H.R.; Buckley, A.R.; Cooperberg, P.L.; Fix, C.H. Sonographic Examination of the Carotid Arteries. Radiographics 2005, 25, 1561-1575. [CrossRef]

44. Cho, M.; Kim, J.; Cho, S.H. A bio-impedance measurement system for portable monitoring of heart rate and pulse wave velocity using small body area. In Proceedings of the 2009 IEEE International Symposium on Circuits and Systems (ISCAS), Taipei, Taiwan, 24-27 May 2009; pp. 3106-3109. 
45. Mancia, G.; Ferrari, A.; Gregorini, L.; Parati, G.; Ferrari, M.C.; Pomidossi, G.; Zanchetti, A. Control of blood pressure by carotid sinus baroreceptors in human beings. Am. J. Cardiol. 1979, 44, 895-902. [CrossRef]

46. Thomas, P.K.; Mathias, C.J. Chapter 52-Diseases of the Ninth, Tenth, Eleventh, and Twelfth Cranial Nerves. In Peripheral Neuropathy, 4th ed.; Dyck, P.J., Thomas, P.K., Eds.; W.B. Saunders: Philadelphia, PA, USA, 2005; pp. 1273-1293. [CrossRef] 